
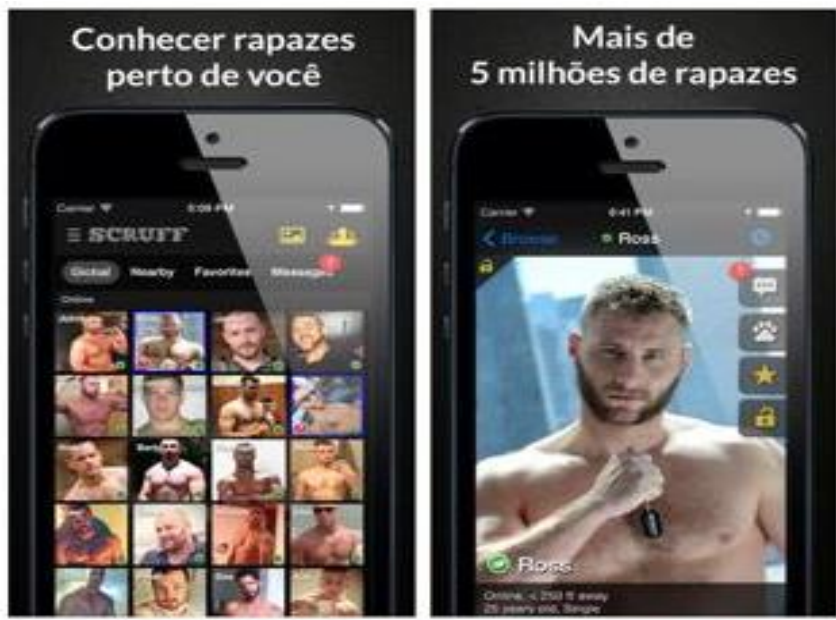

\title{
Cidade e Tecnologia: corpo e afeto no laço geossocial
}

City and Tecnology: body and affection in the geosocial contract

Marcos Aurélio Barbai ${ }^{1}$

\section{Resumo:}

O objetivo deste artigo é o de refletir sobre os processos de significação e o laço social amoroso no mundo contemporâneo. Para isto, escolhi como material de análise os perfis de alguns usuários do aplicativo para smartphones Scruff, que se propõe como uma rede social de encontros amorosos para homens gays. Interessa-me, no trabalho com este aplicativo, pensar a entrada no sujeito na ordem de um discurso que pressupõe a sua enunciação. Trabalho com a hipótese de que o laço amoroso em tempos de aplicativo de celular, através da ferramenta da geolocalização, produz uma sincronia entre corpo e presença subjetiva. Denomino esta sincronia através do conceito de georefêrencia, o ato que entrelaça corpo, presença, conexão na busca do bom objeto amoroso.

Palavras-chave: enunciação; perfil; aplicativo; Scruff; georeferência

\section{Abstract:}

The aim of this article is to reflect on the processes of signification and love social contract in the contemporary world. For this, I chose as material analysis some user's profiles from Scruff, a mobile app that establish itself as social network for gay men searching to date. My concern, working on this app, is to think about the entrance of the subject in that discourse order that assumes its utterance. I work with the hypothesis that the loving contract in mobile application times, through the geolocation tools, produces a synchronicity between body and subjective presence. I call this synchronicity through the concept of georeference, the act that interweaves body, presence, connection in the pursuit of good love-object.

Keywords: utterance; profile; application; Scruff; georeference

\footnotetext{
${ }^{1}$ Pesquisador do Laboratório de Estudos Urbanos/Nudecri da Unicamp. E-mail: barbai@unicamp.br Endereço: Labeurb - Laboratório de Estudos Urbanos Unicamp/Cocen / Nudecri Caixa Postal 6166 Campinas/SP - Brasil. CEP: 13083-892
} 
Para pensar os processos de significação na contemporaneidade, sobretudo no que diz respeito ao laço social que se tece na relação entre subjetividade, cidade e tecnologia, elegi como lugar de reflexão e de análise, a leitura e funcionamento de um aplicativo de celular, o Scruff, configurado e estruturado para produzir uma rede de sociabilidade gay, particularmente entre homens.

$\mathrm{Na}$ leitura deste aplicativo interessa-me pensar a entrada do sujeito na ordem de um discurso que pressupõe a sua enunciação. Quero refletir o jogo entre corpo e enunciação, particularmente a enunciação que não faz série e, para isto, vou me deter nos perfis de usuários que compõem a rede dos scruff guys, o corpo scruff.

Assim, antes de ir diretamente ao aplicativo (porque o que vou apresentar aqui são movimentos iniciais de análise) tomo como lugar de entrada e de visibilidade do discurso, a circulação do dizer sobre os encontros mediados pela tecnologia. Para isso apresento três recortes de um TAB veiculado pelo UOL.

O TAB é uma experiência de conteúdo de informação e interatividade para que o público da internet, uma vez acessando a página do site UOL, na segunda-feira (dia de maior trânsito de internautas pela página do provedor de internet) acesse em formatos criativos e interativos, um conteúdo de qualidade abordando, em diferentes perspectivas, temas contemporâneos, entre eles "sustentabilidade, mobilidade, consumo, comportamento, tecnologia", segundo o diretor de conteúdo UOL, Rodrigo Flores - (cf. http://noticias.uol.com.br/ultimas-noticias/redacao/2014/10/13/uol-lanca-o-tab-novoprojeto-editorial-interativo.htm).

Explicito que este meu primeiro ato, com o TAB, já é na verdade um gesto de análise. Interessa-me observar aqui como os lugares de enunciação são determinados pelo discurso sobre (cf. Orlandi, 1990, Mariani 1998 e Costa 2014). Por discurso sobre tomo como referência teórica o fato de algumas formações imaginárias regerem o semblante dos laços sociais que funcionam em um discurso, representando na temporalidade a memória e história desses laços. De fato, esses discursos enunciam e transmitem algum conteúdo e conhecimento que funcionam como um saber já reconhecido, portanto interpretado, que fala os sujeitos. Há o funcionamento do préconstruído aqui: um efeito de já-dito no discurso. Esse discurso fala por, ele não dá voz ao sujeito. Observemos: 

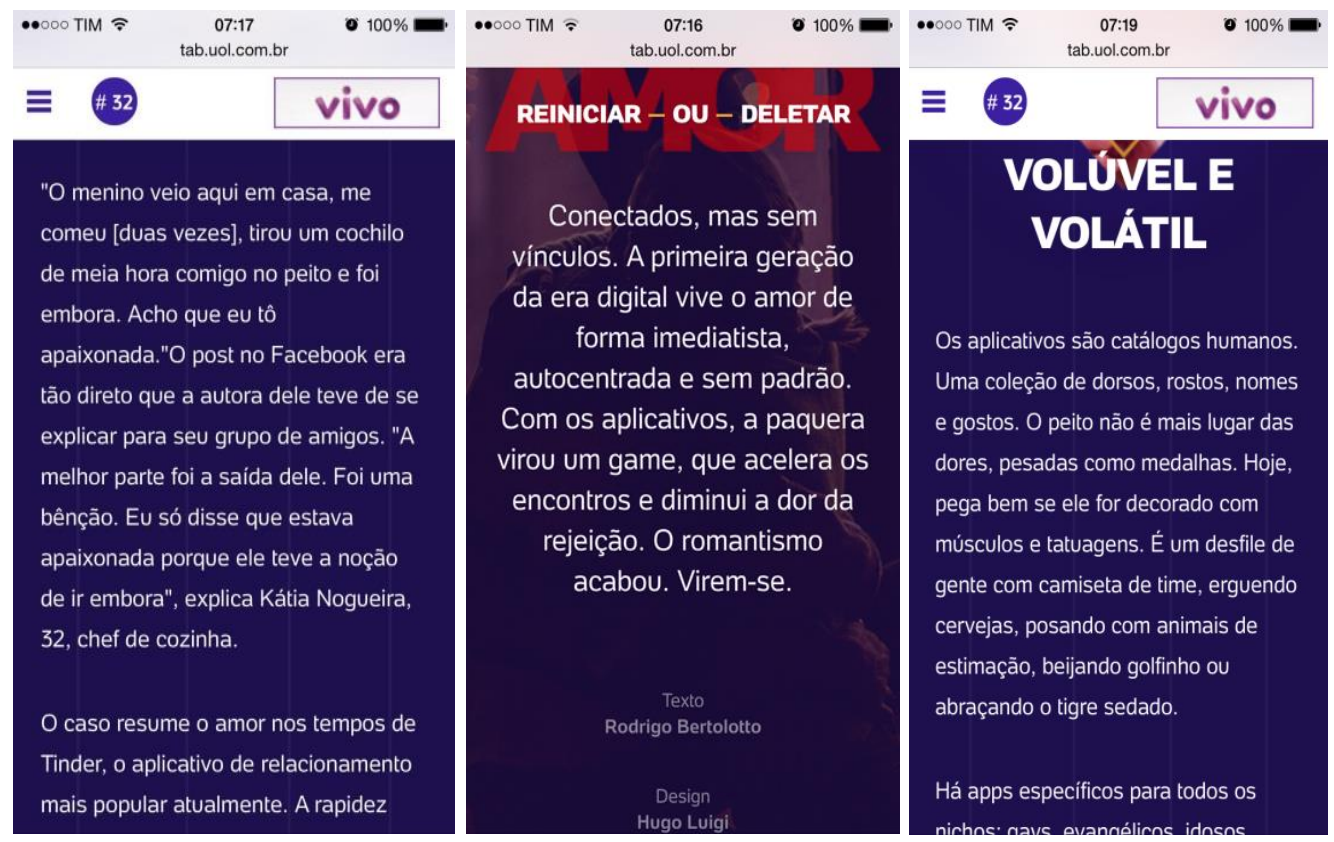

Uma breve leitura desse conteúdo me permite aqui articular uma interessante série: "sem vínculo; imediatista; game; catálogos humanos; nichos; rapidez" que, pelo efeito metafórico, isto é, um dizer que faz o mesmo se repetir no diferente, produz a evidência para uma dada realidade: o amor em tempos de tecnologia, o amor contemporâneo.

Institui-se assim uma memória do amor contemporâneo, em que os encontros amorosos, atravessados e constituídos pelos dispositivos tecnológicos, são eles mesmos parte desse programa, desse sistema. O encontro é uma ferramenta eletrônica de aplicação. O sujeito um banco de dados. E o amor um dispositivo móvel. No contemporâneo os encontros são uma ferramenta social disponível para os clientes. O cliente tem o poder de iniciar, reiniciar e deletar. Este série me permite aqui inscrever duas questões: pode a tecnologia produzir o encontro, o amor e o sexo seguro? É o amor uma plataforma capitalista instalada em nosso tempo para a distribuição e o favorecimento de encontros subjetivos? A humanidade, como diz Michel Pêcheux (1969), pode resistir a essa pechincha?

\section{Encontro e tecnologia: da satisfação ao gozo?}

Em nossa sociedade contemporânea um discurso que circula com força e atualidade é o do fracasso no amor. Há assim um impasse do amor, que toca de modo singular o tempo do homem e da mulher no encontro do parceiro amoroso. Tempo esse que se recobre em uma marca: tempo de idealização que joga com a satisfação do gozo 
- "será que estou satisfeito o bastante ou seria possível sê-lo mais ainda" (cf. Izcovich, 2015, p. 13).

Nessa época atual a satisfação do gozo ${ }^{2}$ é um mote. Ela se liga a uma exigência endereçada que exclui o amor. "O amor tem uma relação com o Um, ou seja, fazer de dois, Um. O gozo tem relação com o Um, mas é Um sozinho. Mesmo quando acreditamos que com dois gozos chegamos a fazer um, por exemplo, ter orgasmo ao mesmo tempo, resta o fato de que não sabe nada sobre o gozo do outro, pois o gozo do outro é sempre o gozo do próprio corpo" (idem, p. 14).

A satisfação do gozo, demanda de nossa época atual, pode ser observada através de uma demanda intransitiva: "que ele me ame". Esquece-se nessa demanda que a abordagem do parceiro sexual não se faz a partir do amor, mas a partir do desejo. "Eu te desejo, mesmo se eu não sei disso." (idem). Está aqui em jogo dar uma chance ao amor que seja outra coisa além da demanda: me satisfaça! A satisfação coloca em cena o que é da ordem do substituível: se é sempre substituível por um outro. A questão do amor coloca em cena o gozo real: "é porque é ele ou porque é ela e nenhum outro [que] nada o substitui." (idem).

Por outro lado, e para não cair nos jogos discursivos da normalidade sexual, que prega a ideia de que existe um "bom objeto", isto é, um parceiro perfeito no plano do desejo, do gozo e do amor (dito de outro modo: aquele que não se consegue encontrar) os encontros de gozos inéditos, que acontecem em qualquer momento da vida, são crucias, como diz Izcovich (idem, p. 18), para a autorização sexual.

Eu me pergunto: os aplicativos de encontros disponíveis no mercado atual seriam eles uma tecnologia de gozo a serviço da (in)satisfação amorosa e sexual? Como ler esses dispositivos eletrônicos que permitem o contato entre as pessoas, margeado pela localização no espaço da cidade, para além da ideia de sistema, de programa de amor? No comércio tecnológico amoroso contemporâneo, como vendem e são vendidos os sujeitos? Aposto aqui na ideia de uma identificação do corpo, como semblante localizável no mundo. O que produz um amor seguro capaz de afastar qualquer contingência.

\footnotetext{
${ }^{2} \mathrm{O}$ gozo é tudo aquilo que produz prazer no corpo. O gozo é a materialidade na qual opera a psicanálise. No gozo há um corpo que fala.
} 


\section{Rede de encontros móveis}

Eu parto aqui do pressuposto de que cada discurso escreve uma gramática do amor. E o discurso da tecnologia, atravessado e constituído pelo capitalismo, não seria diferente. É possível administrar, gerenciar, sistematizar e fazer acontecer o amor através de um sistema eletrônico? Algumas muitas pessoas compram e vendem essa ideia. Entretanto, o que determina essa discursividade e sua enunciação é a rede que se tece quando pessoas se registram no sistema e partilham a sua localização, produzindo assim uma relação. Essa relação não é só escrita de um sistema, de um software de encontro. Há ali, com as pessoas, o conhecer, o apreender e o saber-fazer que é o amor. Uma vez na rede eu informo, com meu corpo, algo do encontro, do erótico e do amor. E isso se constrói através de uma novidade avassaladora: em mobilidade.

Laousse (2004, p. 50) destaca que a mobilidade tem um papel revelador nas transformações da vida cotidiana: ela inovou a maneira como vivemos as atividades de nosso dia-a-dia - a mobilidade, sempre articulada entre o físico (se deslocar), o social (aceder) e o virtual (navegar), transformou-se em ferramenta eletrônica de navegação e comunicação. Ela permitiu outro modo de se geolocalizar no espaço otimizando contatos e impondo, para o autor, um peso da disponibilidade permanente (idem, p. 51).

A mobilidade, sobretudo a que se vive com os dispositivos eletrônicos, afetou o modo como vivemos espacialmente a cidade. O ritmo regular dos lugares, muitas vezes vividos pelos territórios restritos, se amplia: o que amplia ainda (cf. Mizuko e Daisuke, 2004) os encontros. E isso é resultado da dinâmica da conexão que a rede constrói. Há algo da rede que hoje orienta os encontros. Há uma diferença, penso, entre orientar e determinar os encontros. E isso porque há a resistência dos sujeitos.

O grande efeito dos dispositivos de geolocalização, nos dispositivos móveis e aplicativos, é o fato de que ele permite o uso dos lugares. Em um aplicativo de encontro esse lugar em uso é o corpo, a imagem que se edita de si. Imagem tecida para uma rede de conexão e oportunidades de encontro. O corpo é assim a sede das coordenadas geográficas gerenciadas por um terminal eletrônico. Produz-se assim, uma vez no aplicativo de encontro, pela funcionalidade da geolocalização, uma sincronia entre corpo e presença. Proponho aqui chamar essa sincronia entre corpo e presença de georeferência. É essa georeferência que produz o sentimento e os paradoxos subjetivos da imagem sexuada.

Os encontros margeados pela tecnologia móvel são um efeito da nova economia sexual em que o encontro do parceiro é administrado pela ferramenta da escolha 
instantânea: escolha, portanto! Todo aparelhamento de linguagem e política comercial de tecnologia é sustentado por esse imperativo. Escolhe-se um corpo em atividade e não um acontecimento de corpo que é um sujeito, pois isso impõe a ética, um ato de escolha. O encontro erótico produz-se assim hoje, com todo desvelamento da pornografia, como uma modalidade disjunta de toda problemática subjetiva. O capitalismo, como destaca Soler (2015, p. 65), foraclui os problemas de amor, pois sua oferta diz respeito ao funcionamento do mercado, do que pode fazer comércio em tudo que diz respeito aos seres vivos. Até o amor e o sexo.

\section{Um Scruff}

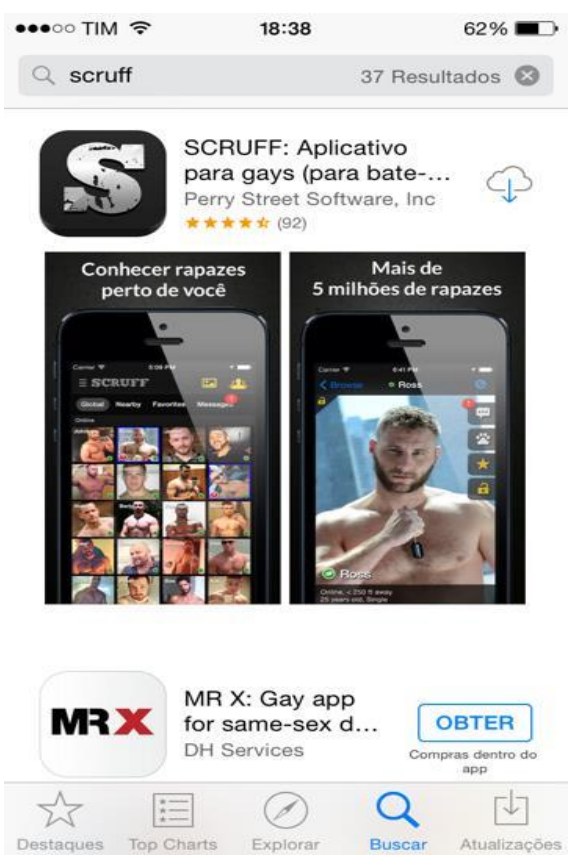

"Conhecer rapazes perto de você. Mais de 5 milhões de rapazes"

"Escolha milhões de caras gays do SCRUFF no seu bairro e ao redor do mundo"

Uma vez na App Store, da Apple ou da Samsung, é deste modo que o possível usuário do aplicativo Scruff será recebido ao pesquisar a palavra e produto. Esse aplicativo de celular, desenvolvido no coração de São Francisco, nos Estados Unidos, foi dirigido primariamente ao encontro de ursos, ou seja, a denominação dada ao homem com barba ou cavanhaque, de peito peludo e corpulento (adulto ou mais velho), na cultura gay ${ }^{3}$. Todavia, esse aplicativo tomou outras proporções: ele produziu hoje uma rede de serviço geosocial gay que reúne mais de cinco milhões de indivíduos, em

\footnotetext{
${ }^{3}$ https://pt.wikipedia.org/wiki/Urso_\%28cultura_gay\%29
} 
180 países. O Scruff, enquanto uma ferramenta de aplicação, cujo acesso virtual articula corpo e localização, tem sido a chave de expansão na contemporaneidade para a sociabilidade gay entre homens. Essa expansão tem produzido no espaço acadêmico questões importantes, tal qual a articuladada por Roth (2013, p. 2114): “está o software móvel do scruff envolvido no processo de construção de uma nova configuração social e espacial da vida gay?"

A questão que me conduz à análise deste aplicativo tem outra dimensão: qual é a política de enunciação que constitui e estabelece o encontro amoroso e sexual atravessado pelos dispositivos de tecnologia móvel? Eu coloco em relevo, com minha interrogação, um conceito que quero propor: a georeferência, isto é, a sincronia entre corpo e presença espacial, na constituição do sujeito na sua relação com o dispositivo móvel: seja ele o celular ou o computador. Que práticas de subjetivação e de linguagem são produzidas nos encontros em redes móveis? Que práticas de subjetivação há no jogo entre usuário e cliente? Essas questões, para as quais não tenho resposta, só podem tomar direção, uma vez circulando pelo aplicativo. É essa viagem que eu proponho hoje, como exercício de análise, de tato com o objeto de leitura e de interpretação.

Um aplicativo como o Scruff, segundo Roth (2013, p. 2114) produz variáveis que motivam o uso do serviço, dentre elas a construção idealizada dos usos e tipos de interação, produzindo uma cibersexualidade que exige a reavaliação das ideias tradicionais de localidade, comunidade, identidade, corpo e sexualidade. Estas, em tempos de tecnologia, são possibilidades de expressão, já que a identidade não é uma construção utópica e divorciada do corpo real e, eu acrescentaria, do corpo virtual.

O Scruff (assim como o Grind, Growing, Hornet, Romeo) é um aplicativo que utiliza os serviços de posicionamento global (GPS) oportunizando via aparelho celular a partilha de localização espacial e informações individuais (foto, idade, peso, altura e uma descrição pessoal) criando uma rede virtual de homens gays. Uma vez na loja do App, o usuário através do download do programa insere seus dados e efetua o cadastro na plataforma. 

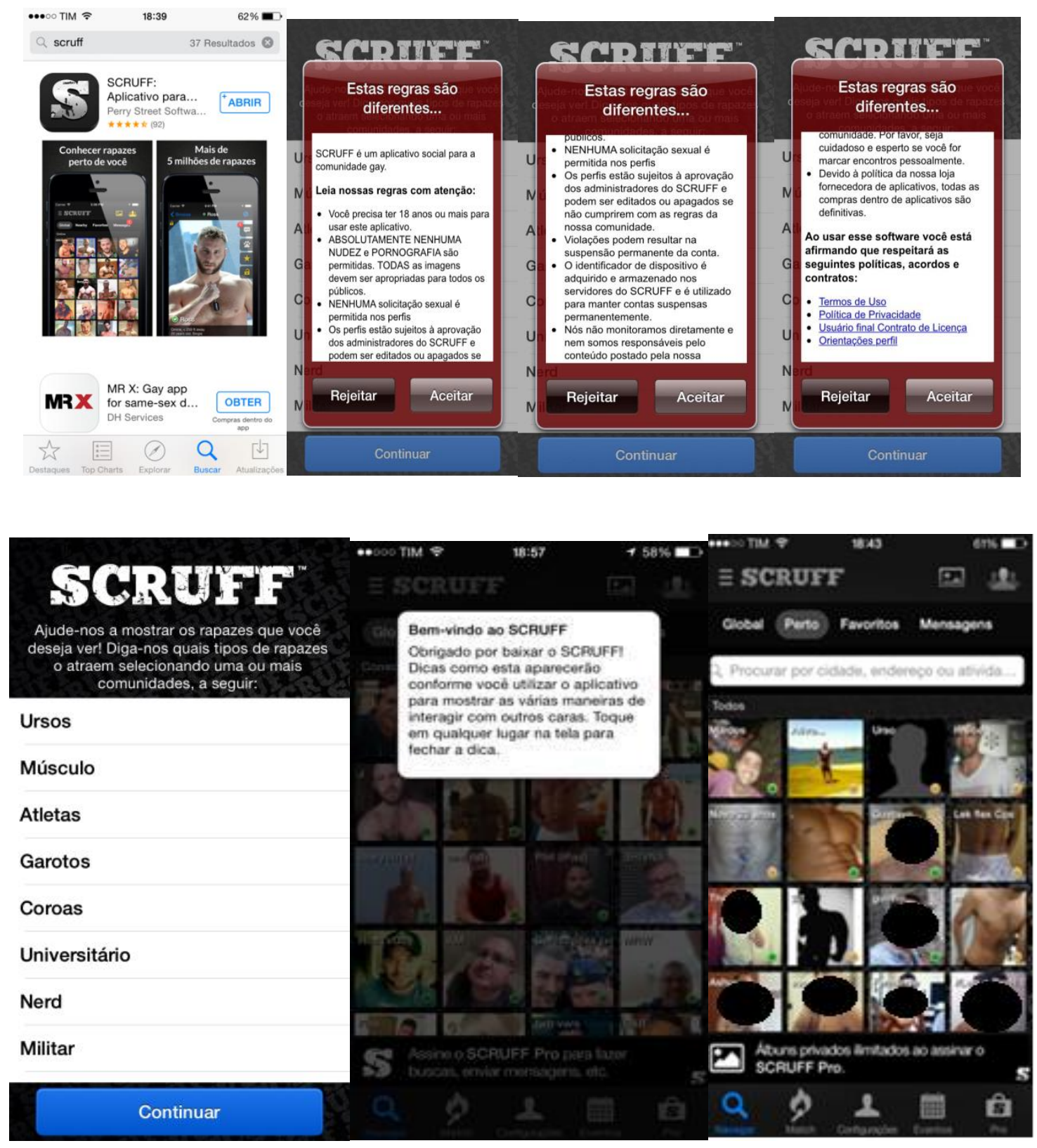

Após responder a um conjunto de questões relativas a termos de serviço e políticas de uso e informação a pessoa tem acesso ao aplicativo via um perfil em que ela deve informar um conjunto de informações que serão visualizadas e acessadas em rede. O aplicativo tem um funcionamento básico: ele localiza via GPS as pessoas mais próximas do usuário em um raio de 10 quilômetros, assim como permite o contato com indivíduos em esfera local, regional, nacional e internacional. A proximidade, que pode ser administrada por filtros, é um dos motes do serviço. A primeira informação provida pela plataforma é a distância do usuário do telefone, em relação à pessoa que pode ser vista em sua tela. A questão da localização é a chave do Scruff (cf. Roth, 2014, p. 2120). 
"Um para um" é a forma de comunicação do aplicativo. O menu de serviço gratuito, porque se pode pagar por uma versão sem filtros e bloqueios do aplicativo, é assim composto: 1) informação referente à distância, raça, altura, peso, pelos no corpo; 2) sou (espaço de descrição); 3) Gosto de; 4? Aberto a; 5) O que faço; 6) O que procuro; 7) Atividades e interesses; 8) Onde moro; 9) Notas; 10) Eventos (cheque-in).

Além disso, o menu de navegação permite quatro operações: Global (usuários no mundo); perto (usuários locais); Favoritos (para marcar pessoas de interesse); Mensagens (para interagir via chat com outros usuários). A isso se acrescenta ainda o menu de usuários: ali se pode enviar e receber Woofs (saudação usada entre os gays ursos); ver o Visitantes de seu perfil; ver os Woofs dados; ver os Woofs vistos, visualizados. Por fim, há a possibilidade de se partilhar álbuns privados, isto é, fotos pessoais que só são acessadas com a autorização e liberação do usuário.

A interatividade das salas de bate-papo, os sites de relacionamento "par perfeito", "namoro online", "gaydar", "manhunt", "Adam4Adam" permitiram, via desktop, o encontro entre pessoas. A novidade dos aplicativos é que a relação se faz entre o toque da tela e a mobilidade. Para Roth (2013, p. 2121) pelo tochscreen o usuário incorpora seu corpo na experiência do uso eletrônico do sistema, transformando-se num scruff guy, um cara scruff. E quem são eles? Apresento-os em 5 recortes:

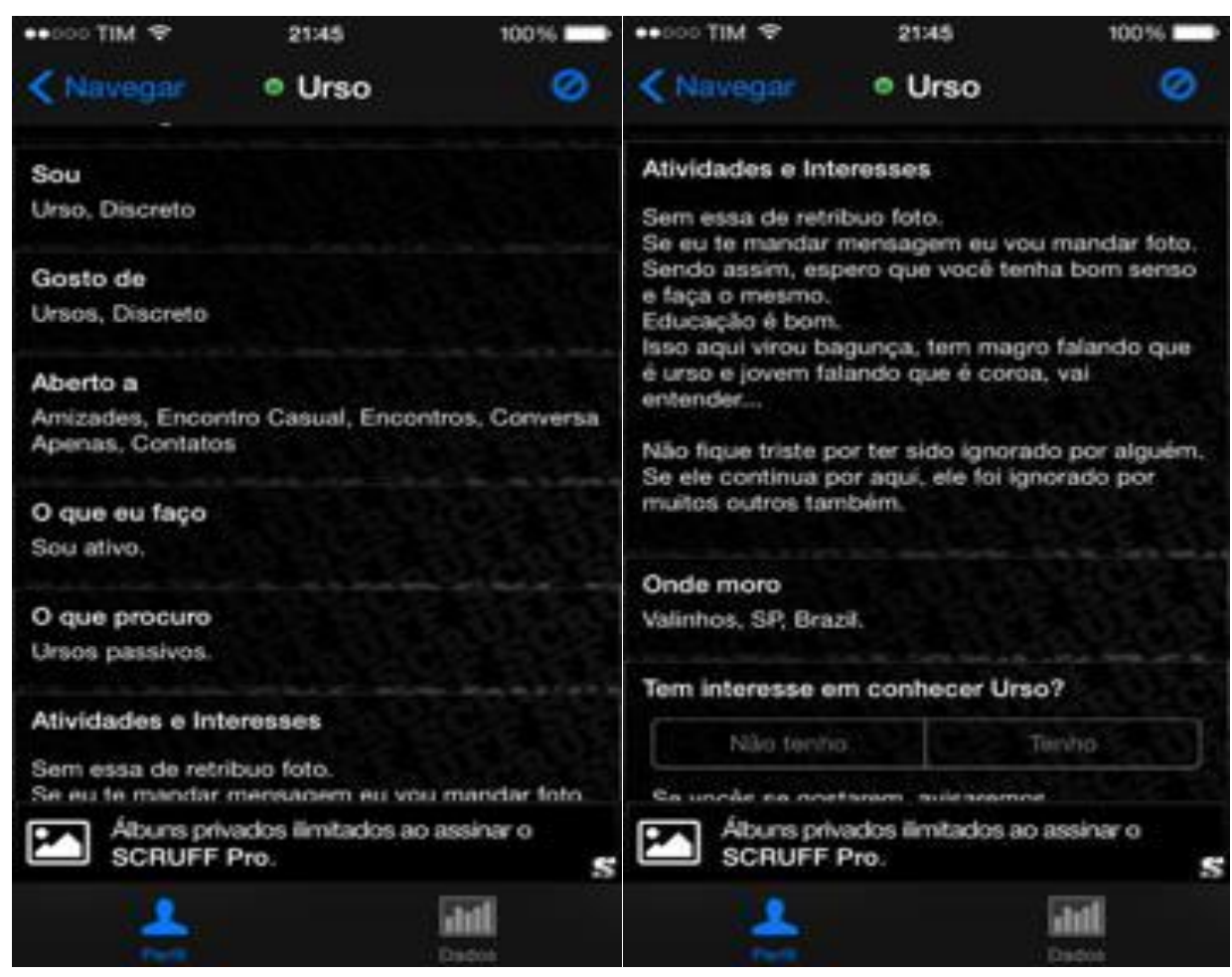




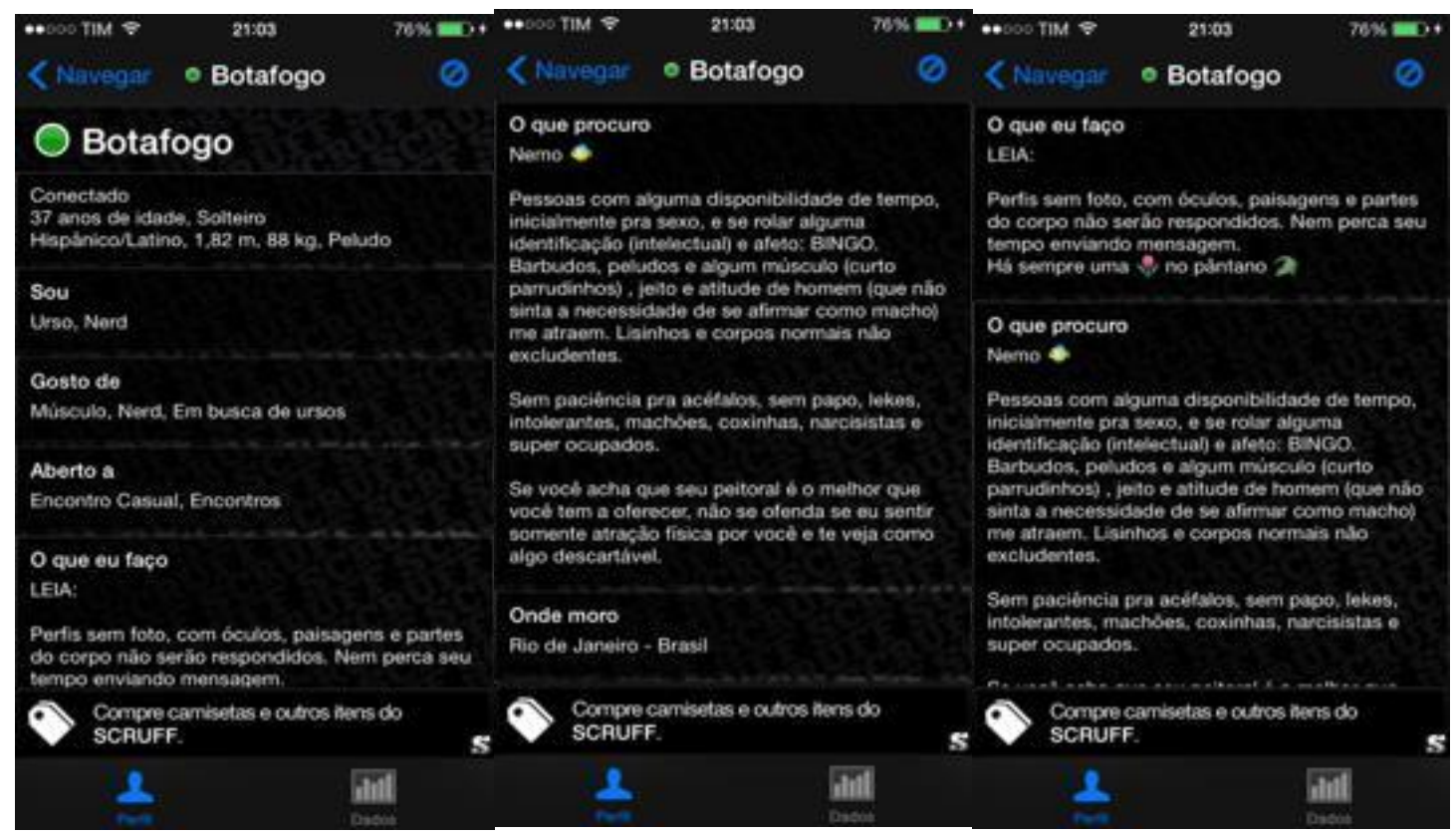

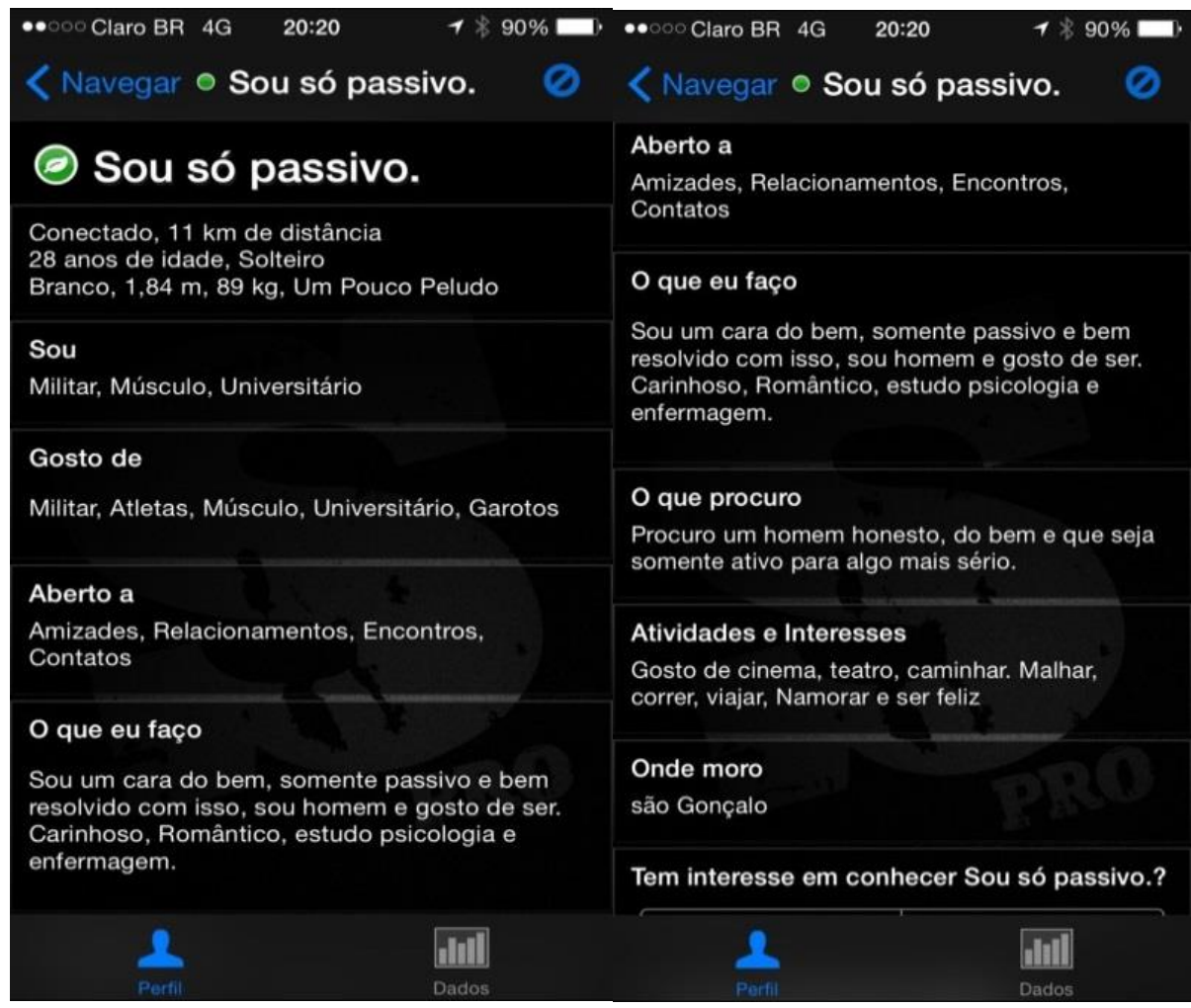




\begin{tabular}{|c|c|}
\hline $\begin{array}{l}17: 49 \\
\text { Navegar } \odot \text { Tall Buddy } \downarrow\end{array}$ & jar O Tall B \\
\hline Tall Buddy $\downarrow$ & $\begin{array}{l}\text { Aberto a } \\
\text { Amizades, Encontro Casual, Encontros }\end{array}$ \\
\hline $\begin{array}{l}\text { Conectado, } 3.7 \text { km de distância } \\
32 \text { anos de idade, Solteiro } \\
\text { Hispânico/Latino, } 1,86 \mathrm{~m}, 84 \mathrm{~kg} \text {, Um Pouco } \\
\text { Peludo }\end{array}$ & $\begin{array}{l}\text { O que eu faço } \\
\text { Deixo as coisas acontecerem; sem pressa!! }\end{array}$ \\
\hline $\begin{array}{l}\text { Sou } \\
\text { Nerd, Em busca de coroas, Discreto }\end{array}$ & \multirow{2}{*}{$\begin{array}{l}\text { O que procuro } \\
\text { Caras desencanados, do bem e sem neuras!! } \\
\text { Nao curto: }\end{array}$} \\
\hline & \\
\hline $\begin{array}{l}\text { Grsos, Militar, Atletas, Em busca de coroas, } \\
\text { Discreto }\end{array}$ & $\begin{array}{l}\text { "Passivos ortodoxos, } \\
\text { "Menores de } 23 \text { anos; } \\
\text { " mulas sem cabeça; }\end{array}$ \\
\hline $\begin{array}{l}\text { Aberto a } \\
\text { Amizades, Encontro Casual, Encontros }\end{array}$ & $\begin{array}{l}\text { * "brother macho, real agora, discreto afim, } \\
\text { dotado flex, sarado real"... rapem fora! }\end{array}$ \\
\hline on & Português, español or english! \\
\hline O que eu faço & 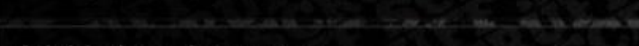 \\
\hline Deixo as coisas acontecerem; sem pressa!! & $\begin{array}{l}\text { Atividades e Interesses } \\
\text { Deixo a vida me levar... }\end{array}$ \\
\hline O que proc & 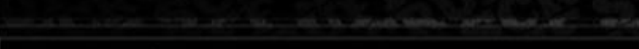 \\
\hline $\mathrm{H}$ & de mensagens ilimita \\
\hline $\begin{array}{llll}\text { Dados } \\
\text { Dados }\end{array}$ & Dados \\
\hline
\end{tabular}

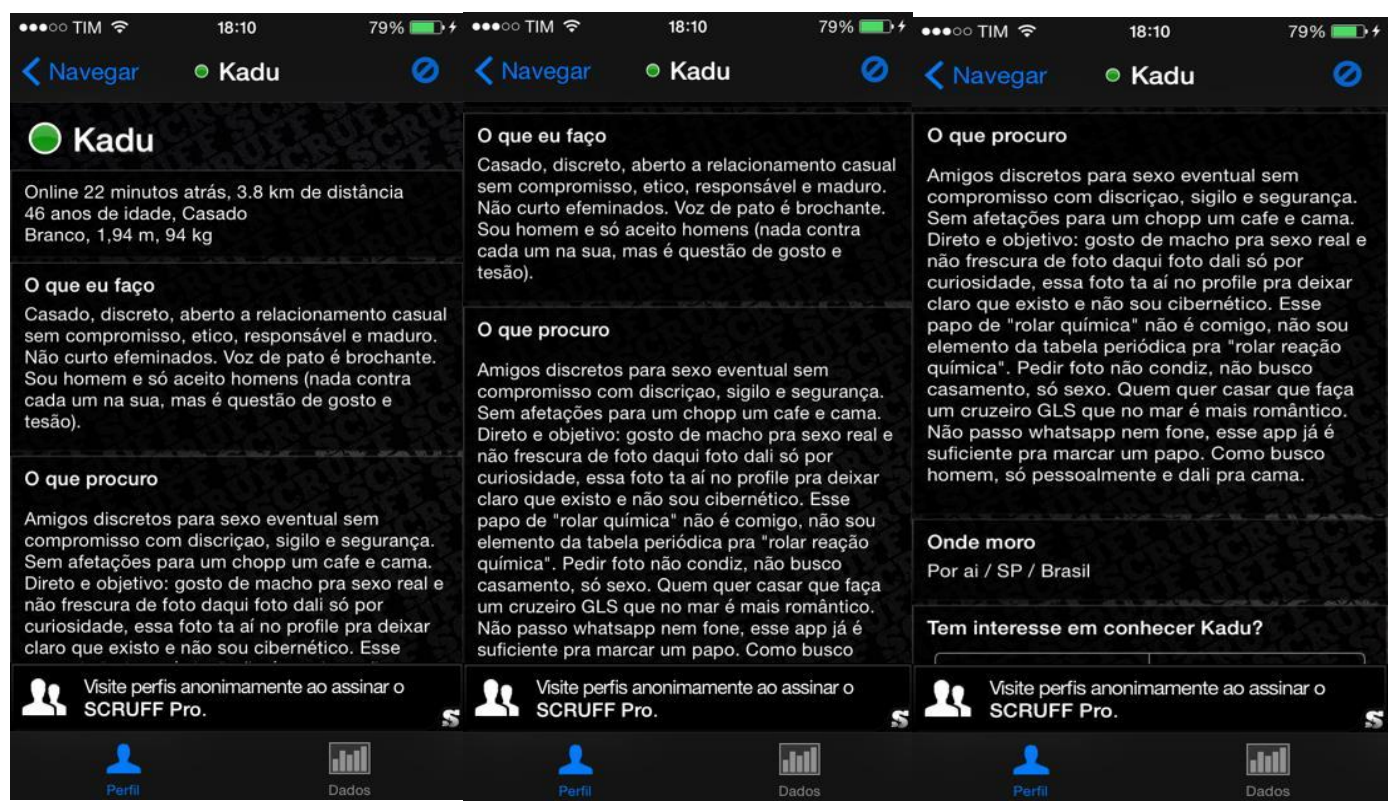

Destes seis recortes aqui apresentados optei, enquanto recurso metodológico e elemento preliminar de análise, em não apresentar a fotografia dos perfis usuários. Os perfis "Botafogo" e "Urso" não apresentam uma imagem de si (face) ou de seu corpo no aplicativo. Os outros três recortes os usuários apresentam a fotografia de face, o que coloca em evidência uma demanda dos usuários do aplicativo, a imagem de si, a aparência. Há ainda a questão da nomeação (um modo particular do léxico em que o 
usuário se denomina: chamo atenção, por exemplo, para o recorte "Sou só passivo" que faz do nome uma declaração antes de qualquer pergunta; e ainda "Botafogo", em que o nome do bairro é o elemento de identificação do usuário).

Há, ainda, a categoria sou. Ela é aqui muito importante, porque as palavras selecionadas para dizer de si mesmo são opções lexicais apresentadas pelo aplicativo. De fato, o aplicativo enquanto cena de enunciação determina o sentido do "sou" do usuário. E essa determinação é construída através de etiquetas discursivas que procuram comunicar algo do universo gay contemporâneo: militar, nerd, passivo, ativo, urso, casado e, o mais intrigante, discreto. A palavra "discreto" é, nas navegações que fiz pelo aplicativo, a que mais se repete. Eu me pergunto assim o que discreto, enquanto acontecimento de corpo em repetição, pode e quer dizer? Há, também, um elemento curioso: todo um jogo de ironia e, às vezes, de violência lexical que se materializa em palavras que classificam o gay: afeminado, lisinhos, do meio gls. Trata-se daqui e um aplicativo para gay em que, às vezes, não se tolera o encontro com o "gay”. Há algo da enunciação que não faz série, que recusa uma memória.

O importante destacar o modo como a finalidade do aplicativo é apresentada: "o que procuro". A expressão "o que procuro" é uma resposta a uma demanda de mercado: o encontro com "mais de cinco milhões de rapazes" e, dentre esses, alguns de seu bairro. Essa expressão é também preenchida por um catálogo disponibilizado pelo aplicativo. Dos recortes aqui apresentados tem-se uma série: amigos, amizade, encontros casuais, relacionamentos, contatos. Essas expressões apontam para um universo de relação, em que uma relação não existe. Ela faz do encontro um instante de redução, um instantâneo. O momento alvo é o sexo, o prazer, a foda. Há algo do ser Um com o outro que fica obliterado. Não se trata de uma procura contingente. Trata-se de uma procura que "é", uma procura do instante. O sujeito que é muitas vezes uma resposta enunciativa do aplicativo reflete com seu corpo a normatividade de como os corpos devem ser expressos, identificados e subjetivados online. Há nesse processo, penso, algo destacado por Roth (2013, 2124): a expressão de si é uma forma de autenticação. E essa autenticação é o que dá passaporte para o mundo das relações online.

Os aplicativos móveis de encontros são uma ferramenta da complexa relação entre o corpo e a geografia da cidade. Eles impõem enquanto dispositivo de enunciação e de edição da imagem de si, a proximidade como o elemento físico e simbólico do 
encontro. O que sustenta a georeferência (corpo e presença de si) é a possibilidade de encontrar um homem no mundo. Este é o mote do aplicativo: um serviço de busca na geografia da cena gay. A busca é o que conecta a presença com a geografia física, a localidade. A busca, como a oferta do encontro do parceiro (sexual, amoroso), do “objeto bom", é um dos itens vendidos pelo mercado de Internet de conexão móvel. Esse encontro nunca foi tão potencial: ele pode acontecer a qualquer hora, em qualquer lugar. Tem-se assim a subversão do espaço e do tempo. O que torna a relação entre cidade e tecnologia uma questão de política subjetiva e de política de mercado. Para um bom encontro é preciso somente estar conectado ao seu celular. A ordem do discurso nunca foi tão sedutora.

\section{Referências Bibliográficas}

COSTA, Greciely Cristina. Sentido de milícia: entre a lei e o crime. Campinas: Editora da Unicamp, 2014.

IZCOVICH, Luiz. Os nós do amor e dos gozos. In: STYLUS: revista de psicanálise, n. 30, junho de 2015. Rio de Janeiro: Associação Fóruns do Campo Lacaniano, p. 13-20.

LAOUSSE, Dominique. Chronosapiens, le navigateur urbain. In: KAPLAN, Daniel \& LAFONT, Hubert (org). Mobilités.net: villes, transport, technologies face aux nouvelles mobilités. Questions numériques, coédition FING-LGDJ, 2004, p. 50-54.

MIZUKO, Ito e DAISUKE, Okabe. La rencontre augmentée. In: KAPLAN, Daniel \& LAFONT, Hubert (org). Mobilités.net: villes, transport, technologies face aux nouvelles mobilités. Questions numériques, coédition FING-LGDJ, 2004, p. 167-170.

MARIANI, Bethania. O Pcb e a imprensa. Campinas: Editora da Unicamp, 1998.

ORLANDI, Eni Puccinelli. Terra à vista. Campinas: Editora da Unicamp, 1990.

ROTH, YOEL. Locating the "Scruff guy": theorizing body and space in gay geosocial media. In: International Journal of Communication 8 (2014) 2113-2133. http://ijoc.org/index.php/ijoc/article/view/2286/1192

SOLER, Colette. Nova economia sexual. In: STYLUS: revista de psicanálise, n. 30, junho de 2015. Rio de Janeiro: Associação Fóruns do Campo Lacaniano, p.59-68. 


\section{Para citar essa obra:}

BARBAI, Marcos Aurélio. Cidade e Tecnologia corpo e afeto no laço geossocial In: RUA [online]. $\mathrm{n}^{\circ}$. 22. Cidade Conectada, p. 301-313 - ISSN 1413-2109/e-ISSN 21799911 - outubro/2016. Consultada no Portal Labeurb - Revista do Laboratório de Estudos Urbanos do Núcleo de Desenvolvimento da Criatividade.

http://www.labeurb.unicamp.br/rua/

Laboratório de Estudos Urbanos - LABEURB

Núcleo de Desenvolvimento da Criatividade - NUDECRI

Universidade Estadual de Campinas - UNICAMP

http://www.labeurb.unicamp.br/

Endereço:

LABEURB - LABORATÓRIO DE ESTUDOS URBANOS

UNICAMP/COCEN / NUDECRI

CAIXA POSTAL 6166

Campinas/SP - Brasil

CEP 13083-892

Fone/ Fax: (19) 3521-7900

Contato: http://www.labeurb.unicamp.br/contato 